\title{
ADDENDUM
}

\section{Magnetoferritin nanoparticles for targeting and visualizing tumour tissues}

Kelong Fan, Changqian Cao, Yongxin Pan, Di Lu, Dongling Yang, Jing Feng, Lina Song, Minmin Liang and Xiyun Yan

Nature Nanotechnology 7, 459-464 (2012); published online 17 June 2012; corrected after print 22 October 2012.

Editorial note: A potential breach of our editorial policies has emerged following the publication of this paper. Yongxin Pan and Changqian Cao, who are listed as contributing authors, have declared no knowledge of the submission of the paper, and their disagreement with its publication. They have pointed out several errors in the description of the synthesis and characterization of the magnetoferritin nanoparticles used in the study. We take breaches of editorial policies very seriously and have therefore informed the listed authors' institutions and the Chinese Academy of Sciences. 